\title{
PET of Glucagonlike Peptide Receptor Upregulation After Myocardial Ischemia or Reperfusion Injury
}

\author{
Haokao Gao*1,2, Dale O. Kiesewetter*2, Xiaoxiang Zhang ${ }^{2}$, Xinglu Huang ${ }^{2}$, Ning Guo $^{2,3}$, Lixin Lang ${ }^{2}, \mathrm{Naoki} \mathrm{Hida}^{2}$, \\ Hui Wang ${ }^{2}$, Haichang Wang ${ }^{1}$, Feng $\mathrm{Cao}^{1}$, Gang Niu ${ }^{2}$, and Xiaoyuan Chen ${ }^{2}$ \\ ${ }^{I}$ Department of Cardiology, Xijing Hospital, the Fourth Military Medical University, Xi'an, China; ${ }^{2}$ Laboratory of Molecular Imaging \\ and Nanomedicine (LOMIN), National Institute of Biomedical Imaging and Bioengineering (NIBIB), National Institutes of Health \\ (NIH), Bethesda, Maryland; and ${ }^{3}$ Center for Molecular Imaging and Translational Medicine, School of Public Health, Xiamen \\ University, Xiamen, China
}

Glucagonlike peptide (GLP-1) and its receptor (GLP-1R) exhibit cardioprotective effects after myocardial ischemia and reperfusion $(\mathrm{Ml} / \mathrm{R})$ in both animal studies and clinical trials. However, the kinetics of GLP-1R expression in the infarcted/ischemic myocardium has not yet been explored. The purpose of this study was to monitor the presence and time course of regional myocardial GLP1R expression after MI/R with noninvasive PET. Methods: Male Sprague-Dawley rats underwent a 45-min transient left coronary artery occlusion, followed by reperfusion. The myocardial infarction was confirmed by electrocardiogram and cardiac ultrasound. In vivo PET was performed to determine myocardial uptake of ${ }^{18} \mathrm{~F}$ FBEM-Cys ${ }^{40}$-exendin- 4 at different time points after reperfusion. The localization of ${ }^{18} \mathrm{~F}$-FBEM-Cys ${ }^{40}$-exendin-4 accumulation was determined by coregistering ${ }^{18} \mathrm{~F}-\mathrm{FDG}$ PET and CT images. Ex vivo autoradiography, GLP-1R immunohistochemical staining, and Western blot analysis were performed to confirm the PET results. Results: Myocardial origin and infarcted/ischemic area localization of ${ }^{18} \mathrm{~F}$-FBEM-Cys ${ }^{40}$-exendin-4 accumulation was confirmed by coregistration of small-animal CT and ${ }^{18} \mathrm{~F}-\mathrm{FDG}$ images. At $8 \mathrm{~h}$ after $\mathrm{Ml} / \mathrm{R}$, tracer uptake in the infarcted/ischemic region was $0.37 \pm$ 0.05 percentage injected dose per gram, significantly higher than that in the control group $(P<0.01)$. The localized tracer uptake decreased, relative to the 8-h time point, but was still significantly higher than the control group on days 1 and 3 after Ml/R. At 2 wk after $\mathrm{MI} / \mathrm{R}$, the tracer uptake in the affected area showed no significant difference, compared with that in the healthy myocardium. Autoradiography showed the same trend of ${ }^{18} \mathrm{~F}-\mathrm{FBEM}-\mathrm{Cys}^{40}$ exendin-4 uptake in the myocardial infarcted/ischemic area. The specificity of tracer uptake into ischemic myocardium was supported by decreased tracer uptake after the rats were pretreated with an excess amount of unlabeled exendin-4. Immunohistochemical staining and Western blotting of GLP-1R protein of excised cardiac sections confirmed that the change in uptake observed by PET corresponded to a change in GLP-1R expression. Conclusion: Noninvasive PET using ${ }^{18} \mathrm{~F}-\mathrm{FBEM}-\mathrm{Cys}^{40}$-exen-

Received Jul. 13, 2012; revision accepted Jul. 24, 2012.

For correspondence or reprints contact either of the following:

Feng Cao, Department of Cardiology, Xijing Hospital, the Fourth Military

Medical University, Xi'an, China 710032

E-mail: wind8828@gmail.com

Gang Niu, 10 Center Dr., 10/B3B25, Bethesda, MD 20892-2281.

E-mail: niug@mail.nih.gov

${ }^{*}$ Contributed equally to this work.

Published online Nov. 8, 2012.

COPYRIGHT @ 2012 by the Society of Nuclear Medicine and Molecular Imaging, Inc. din-4 revealed a dynamic pattern of GLP-1R upregulation in the infarcted/ischemic area after $\mathrm{Ml} / \mathrm{R}$. The imaging results will deepen our understanding of the mechanism of the cardioprotective effect of GLP-1 and its analogs and potentially provide guidance for optimization of the time frame of therapeutic intervention.

Key Words: PET imaging; GLP-1R; myocardial infarction; exendin 4

J Nucl Med 2012; 53:1960-1968

DOI: 10.2967/jnumed.112.109413

$\mathbf{A}_{\text {s the leading cause of death in the world, coronary }}$ heart disease claims the lives of 3.8 million men and 3.4 million women each year throughout the world (1). After an acute coronary artery occlusion, restoring coronary patency using either primary percutaneous coronary intervention or thrombolytic therapy remains the most effective treatment strategy to provide oxygen and nutrients to the ischemic area. However, reperfusion itself also exacerbates myocardial damage, which is known as ischemia/reperfusion injury $(2,3)$. Methods to protect the heart during reperfusion are of great clinical interest. Ischemic conditioning is an innate protective mechanism by which brief ischemia renders the organ resistant to more prolonged and potentially lethal ischemia (4). Both preconditioning and postconditioning involve the activation of specific cell surface receptors, such as several G-protein-coupled receptors, which in turn activate a complex array of intracellular signaling pathways (5).

The glucagonlike peptide type 1 (GLP-1), a 30-amino-acid gut hormone, is released after the ingestion of nutrients. GLP-1 acts through a distinct heptahelical G-protein-coupled receptor (GLP-1R), which is highly expressed in pancreatic $\beta$-cells (6). GLP-1R is also expressed in high density and high incidence in certain types of cancers derived from endocrine, neuroendocrine, and embryonic origins (7). GLP-1 levels are decreased in patients with type 2 diabetes, and GLP-1-based therapies are currently in widespread clinical use for the treatment of type 2 diabetes. 
Emerging evidence indicated that GLP-1 and related peptides have protective effects in a variety of tissues, including the demonstration of cardioprotection in a range of animal models of ischemia and reperfusion (8-10). GLP-1 limits apoptosis in myocytes via activation of cyclic adenosine monophosphate and phosphoinositide 3-kinase by binding with GLP-1Rs (8). It has been demonstrated that phosphoinositide 3-kinase activation is associated with myocardial protection in the setting of ischemic/reperfusion injury (11) and myocardial preconditioning (12). Moreover, activation of the antioxidant gene heme oxygenase-1 through GLP-1R reduces fibrosis and left ventricle (LV) remodeling and restores LV function after myocardial ischemia $(13,14)$. In view of the important cardioprotective role that the GLP-1/GLP-1R pathway plays during MI/R, a noninvasive method for the longitudinal assessment of GLP-1 peptide delivery and regional upregulation of GLP-1R could be of considerable value to accelerate GLP-1-related drug development and improve the understanding of its role in MI/R injury.

Despite the high affinity and specific binding to GLP-1R, native GLP-1 peptide is not ideal as an imaging tracer because it is rapidly degraded by dipeptidyl-peptidase-IV via the cleavage of $2 \mathrm{~N}$-terminal residues (15). Consequently, both synthetic and naturally occurring GLP-1 analogs including exendin-3 and exendin- 4 have been labeled with radioisotopes such as ${ }^{111} \mathrm{In}$ and ${ }^{99 \mathrm{~m}} \mathrm{Tc}$ for SPECT and ${ }^{68} \mathrm{Ga}$ for PET (16-18). Exendin-4 shows a 53\% amino acid homology with GLP-1 but is resistant to dipeptidyl-peptidase-IV attack and, consequently, has a much longer plasma half-life (19). Recently, we developed 2 novel PET probes, ${ }^{18} \mathrm{~F}-\mathrm{FBEM}$-EM3106B and ${ }^{18} \mathrm{~F}-\mathrm{FBEM}-\mathrm{Cys}{ }^{40}$-exendin-4, for GLP-1R-targeted PET $(20,21)$. In an INS-1 rat insulinoma xenograft model, both tracers showed high and receptorspecific tumor accumulation. Compared with the synthetic preparation of the bis-cyclic amide EM3106B, the linear peptide structure of exendin-4 provides easy preparation of $\mathrm{C}$-terminal and $\mathrm{N}$-terminal cysteine modifications using standard solid-phase peptide synthesis methods. The cysteine-modified exendin-4 analog is amenable to radiolabeling using our ${ }^{18} \mathrm{~F}$-FBEM prosthetic group (21).

In the present study, we performed longitudinal PET in a rat MI/R model using ${ }^{18} \mathrm{~F}-\mathrm{FBEM}-\mathrm{Cys}^{40}{ }^{-}$-exendin-4 as the imaging probe. The noninvasive in vivo imaging is expected to provide real-time information as to the presence and time course of regional myocardial GLP-1R expression. To the best of our knowledge, this is the first attempt to use a radiolabeled ${ }^{18} \mathrm{~F}$-labeled GLP-1 peptide analog for myocardial imaging.

\section{MATERIALS AND METHODS}

All reagents were of analytic grade and were obtained from commercial sources. The ${ }^{18} \mathrm{~F}$ radionuclide was obtained from the Clinical Center's cyclotron facility of the National Institutes of Health by proton irradiation of ${ }^{18} \mathrm{O}$-enriched water. ${ }^{18} \mathrm{~F}-\mathrm{FDG}$ was purchased from the Nuclear Pharmacy of Cardinal Health and was reconstituted with sterile saline. $\mathrm{Cys}^{40}$-exendin- 4 and exendin- 4 were prepared by solid-phase peptide synthesis (CS Bio Inc.).

Radiochemical Synthesis of ${ }^{18} \mathrm{~F}-F B E M-C y s^{40}$-Exendin-4

${ }^{18} \mathrm{~F}-\mathrm{FBEM}-\mathrm{Cys}{ }^{40}$-exendin- 4 was prepared with the same procedure as described before (21). The desired amount of ${ }^{18} \mathrm{~F}-\mathrm{FBEM}$ (range, 388.5-984.2 MBq) was evaporated to near-dryness and mixed with $10 \mu \mathrm{L}$ of ethanol (22), and 100-200 $\mu \mathrm{g}$ of $\mathrm{Cys}^{40}$ exendin- 4 in $100 \mu \mathrm{L}$ of $0.1 \%$ sodium ascorbate in phosphatebuffered saline (PBS) was added. The major radioactivity peak collected from the semipreparative high-performance liquid chromatography was the product. The fraction containing ${ }^{18} \mathrm{~F}-\mathrm{FBEM}-$ $\mathrm{Cys}^{40}$-exendin- 4 was diluted to $20 \mathrm{~mL}$ with water and passed through a C-18 BondElut cartridge $(100 \mathrm{mg})$. The product that remained on the cartridge was eluted with $1 \mathrm{~mL}$ of $10 \mathrm{mM} \mathrm{HCl}$ in ethanol. The ethanol eluent was evaporated and redissolved in PBS for animal studies. The radiochemical synthesis yield for ${ }^{18}$ F-FBEM-Cys ${ }^{40}$-exendin-4 was $34.3 \% \pm 3.4 \%(n=11)$ based on starting ${ }^{18} \mathrm{~F}$-FBEM without decay correction. Radiochemical purity was more than $96 \%$.

\section{Animal Model of Coronary Occlusion and Reperfusion}

All animal studies were conducted in accordance with the principles and procedures outlined in the Guide for the Care and Use of Laboratory Animals (23) and were approved by the Institutional Animal Care and Use Committee of the Clinical Center (National Institutes of Health). Adult male Sprague-Dawley rats weighing from 250 to $300 \mathrm{~g}$ were used. Anesthesia was induced with $5 \%$ isoflurane and the animals were intubated for mechanical ventilation. The anesthesia was then maintained with $2 \%$ isoflurane. MI/R models were induced by ligation of the left anterior descending coronary artery $2-3 \mathrm{~mm}$ from the tip of the left auricle with a 6-0 polypropylene suture. Forty-five minutes after the coronary occlusion, the suture was removed to obtain reperfusion. In the sham-operated animals, a suture was placed in the myocardium (without ligation of the left coronary artery). The occlusion and reperfusion were confirmed by ST-segment elevation on an electrocardiogram monitor (EC-60 model; Silogic) and ${ }^{18}$ F-FDG imaging at $1 \mathrm{~d}$ after surgery.

\section{Assessment of LV Contractility with Echocardiography}

Cardiac function was assessed as described previously (24). Briefly, $2 \mathrm{~d}$ after MI/R, the rats received 3\% isoflurane for general anesthesia and were placed on the scanning table. Echocardiographic images were obtained using a dedicated small-animal highresolution imaging unit and a 30-MHz linear transducer (Vevo 770; Visualsonics) (25). LV end-diastolic and LV end-systolic diameters (LVEDD and LVESD, respectively) were measured using the parasternal short-axis view, and LV fractional shortening was calculated as $($ LVEDD - LVESD)/LVEDD $\times 100$. All measurements were averaged on 3 consecutive cardiac cycles.

\section{Small-Animal PET/CT Scanning}

At $8 \mathrm{~h}, 1 \mathrm{~d}, 3 \mathrm{~d}, 1 \mathrm{wk}$, and $2 \mathrm{wk}$ after MI/R, PET and image analysis were performed using an Inveon microPET scanner (Siemens Medical Solutions) (26). Animals were anesthetized with $3 \%$ isoflurane, and approximately $18.5 \mathrm{MBq}(500 \mu \mathrm{Ci})$ of ${ }^{18} \mathrm{~F}-$ FBEM-Cys ${ }^{40}$-exendin-4 was administered via tail vein injection. One hour later, 10-min static PET images were acquired. The images were reconstructed using a 2-dimensional ordered-subset expectation maximum algorithm, and no correction was applied 
for attenuation or scatter. For each scan, regions of interest (ROIs) were drawn using vendor software (ASI Pro 5.2.4.0 VM; Siemens Preclinical Solution) on decay-corrected whole-body coronal images. The radioactivity concentrations (accumulation) within myocardium were obtained from mean pixel values within the multiple ROI volume and then converted to megabecquerels per milliliter. These values were then divided by the administered activity to obtain (assuming a tissue density of $1 \mathrm{~g} / \mathrm{mL}$ ) an image ROI-derived percentage injected dose per gram $(\% \mathrm{ID} / \mathrm{g})$. In addition, signal from the infarcted area was compared with the contralateral myocardium (at the septal level), which was taken as background signal, and expressed as the signal-to-background ratio. To assess the specificity of tracer uptake, $8 \mathrm{mg}$ of unlabeled exendin- 4 per kilogram were injected $10 \mathrm{~min}$ before ${ }^{18} \mathrm{~F}-\mathrm{FBEM}-\mathrm{Cys}^{40}$-exendin-4 (18.5 MBq) administration in rats at $3 \mathrm{~d}$ after $\mathrm{MI} / \mathrm{R}(n=3)$.

Immediately after the ${ }^{18} \mathrm{~F}-\mathrm{FBEM}-\mathrm{Cys}^{40}$-exendin- 4 scan, animals were kept on the scanning gantry (for image coregistration) and injected with $18.5 \mathrm{MBq}(500 \mu \mathrm{Ci})$ of ${ }^{18} \mathrm{~F}$-FDG. One hour afterward, 10-min static images were acquired, with the mid thorax in the center of the field of view, and images were reconstructed and analyzed with the same procedure as described above.

To anatomically localize the tracer signal obtained using PET, animals from both groups were first scanned in an Inveon docked PET/CT scanner (Siemens Medical Solutions). An anesthetized rat was mounted on a turntable bed that could be moved automatically in the axial direction. Respiration-gated CT acquisition parameters were as follows: voltage, $80 \mathrm{kVp}$; current, $400 \mu \mathrm{A}$; angular sampling, $1^{\circ}$ per projection for a full $360^{\circ}$ scan; and effective pixel size, $58 \mu \mathrm{m}$. The scanning time was approximately $10 \mathrm{~min}$. The image was reconstructed in real time by a modified Feldkamp cone-beam algorithm with a Shepp-Logan filter and an appropriate center offset as determined before scanning. A maximum-intensity projection of the CT image was adopted for anatomic reference of PET.

\section{Autoradiography}

At each time point in parallel with PET, the same amount of ${ }^{18}$ F-FBEM-Cys ${ }^{40}$-exendin- 4 was administered to each rat. One hour later, the heart was harvested and frozen in CRYO-OCT compound (Tissue-Tek). Serial short-axis sections covering the entire heart were obtained at $1-\mathrm{mm}$ intervals $(15-\mu \mathrm{m}$ thickness each) using a cryostat (Ultrapro5000; Vibratome). The tissues were flash-thawed onto silanized glass slides. A high-efficiency storage phosphor screen was exposed to the tissue slides for $12 \mathrm{~h}$ and developed in a Cyclone Plus Storage Phosphor System (PerkinElmer). The autoradiograph was analyzed with Optiquant acquisition and analysis software (version 5.0; Perkin Elmer). The ${ }^{18}$ F-FBEM-Cys ${ }^{40}$-exendin-4 uptake ratio was calculated by dividing the ROI value of the focal tracer uptake region by that of the contralateral normal area.

\section{Hematoxylin and Eosin (HE) and 2,3,5-Triphenyl-2H- Tetrazolium Chloride (TTC) Staining}

Slices $(15 \mu \mathrm{m})$ adjacent to those used for autoradiography were selected for HE staining using standard techniques. Slices of 2-mm thickness adjacent to those used for autoradiography and HE imaging were also prepared and stained with a buffered solution of TTC at $38^{\circ} \mathrm{C}$ to identify myocardial infarction.

\section{GLP-1R Immunohistochemical Staining}

Myocardial tissue samples were fixed with $10 \%$ neutral buffered formalin and embedded in paraffin. Tissue sections (thickness, $5 \mu \mathrm{m}$ ) were blocked with endogenous peroxidase using 3\% hydrogen peroxide for $20 \mathrm{~min}$. Sections were then washed 3 times in PBS and briefly in a buffer containing $1 \%$ polymerized bovine albumin and incubated with rabbit antirat polyclonal GLP-1R antibody (1:200; Abcam) at $37^{\circ} \mathrm{C}$ for $2 \mathrm{~h}$. After being washed with PBS, each section was incubated with horseradish peroxidase-conjugated antigoat IgG for $60 \mathrm{~min}$ at room temperature. Diaminobenzidine was used as the chromogen, and HE counterstaining was performed. Six fields were randomly selected from each section and observed using a light microscope (BX41; Olympus).

\section{Fluorescent Staining}

Frozen heart sections from MI/R rats and sham-operated rats (5-8 $\mu \mathrm{m}$ thick) were fixed with cold acetone for $20 \mathrm{~min}$ and dried in the air. All the sections were blocked with $1 \%$ bovine serum albumin for $30 \mathrm{~min}$ and then incubated with rabbit antirat GLP1-R antibody (AGR-02, 1:200; Alomone Labs) and mouse antirat CD11b antibody (MA1-80560, 1:300; Pierce Biotechnology) for $1 \mathrm{~h}$ at room temperature. They were then stained with Dylight 488-conjugated donkey antimouse secondary antibody $(1: 1,000)$ and Cy3-conjugated donkey antirabbit secondary antibody $(1: 1,000$; Jackson ImmunoResearch Laboratories). After 5 washing steps, the tissue slices were mounted with medium containing 4',6-diamidino2-phenylindole, and all slices were observed by an epifluorescence microscope (X81; Olympus).

\section{Western Blot Analysis of GLP-1R}

Myocardial samples (100-200 $\mathrm{mg}$ ) that had been frozen in liquid nitrogen were homogenized and suspended in radioimmunoprecipitation assay (RIPA) buffer (Sigma) plus protease inhibitor cocktail (Roche). Soluble protein fractions $(30 \mu \mathrm{g})$ were separated on $4 \%-12 \%$ polyacrylamide gels using sodium dodecyl sulfate polyacrylamide gel electrophoresis and transferred to nitrocellulose membranes, which were blocked for 1 $\mathrm{h}$ at room temperature with Tris-buffered saline containing 5\% bovine serum albumin. The blots were washed with Tris-buffered saline containing $0.1 \%$ polysorbate 20 and then incubated with rabbit antirat polyclonal GLP-1R antibody (1:500; Abcam). In all determinations, monoclonal antibody for rat glyceraldehyde-3-phosphate dehydrogenase (1:2000; Abcam) was used as an internal control. After extensive washing, the antigen-antibody complexes were detected using horseradish peroxidase-labeled donkey antirabbit IgG and a SuperSignal West Pico Chemiluminescence Kit Detection System (Pierce).

\section{Statistical Analysis}

Data are expressed as mean $\pm \mathrm{SD}$. Statistical analysis used the unpaired Student $t$ test with unequal variance (for comparison between sham-operated and animals with myocardial ischemia) and the paired Student $t$ test for comparison before and after myocardial ischemia. A $P$ value of less than 0.05 was considered statistically significant.

\section{RESULTS}

\section{Characterization of MI/R Model}

The success of the MI/R model was confirmed by ST-T segment elevation using electrocardiography during surgery (Fig. 1A). There was no difference in weight or heart rate between sham $(n=3)$ and MI/R $(n=5)$ animals (data not shown). At $1 \mathrm{~d}$ after surgery, an obvious uptake defect in 


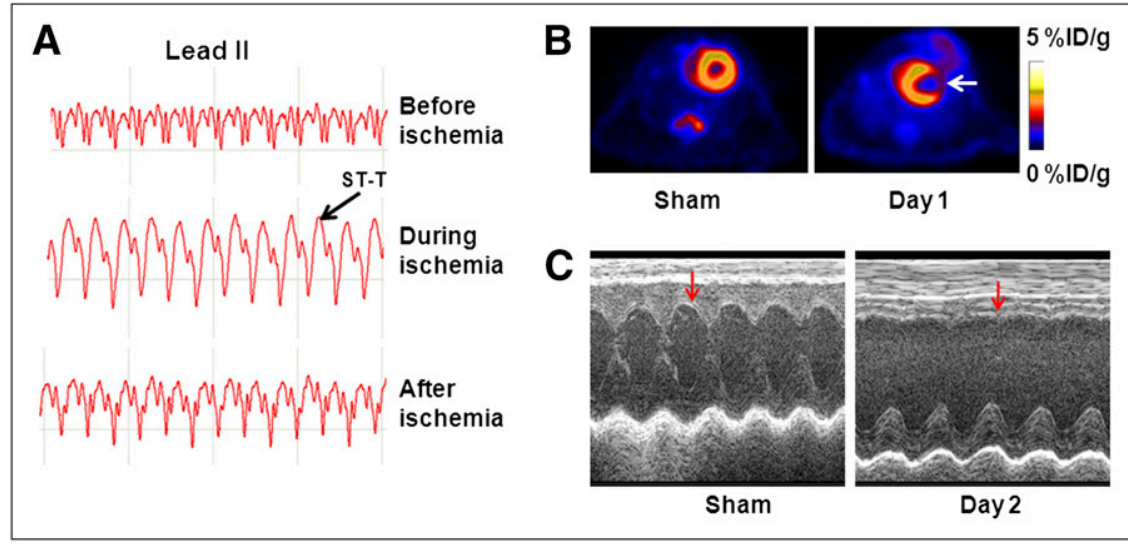

FIGURE 1. Characterization of $\mathrm{MI} / \mathrm{R}$ model. (A) Electrocardiogram change during and after MI/R. (B) ${ }^{18} \mathrm{~F}-\mathrm{FDG}$ PET of shamoperated rats and animal with $\mathrm{Ml} / \mathrm{R}$ at $1 \mathrm{~d}$ after reperfusion. Decreased ${ }^{18} \mathrm{~F}-\mathrm{FDG}$ accumulation was observed in anterolateral wall (white arrow) in heart with $\mathrm{MI} / \mathrm{R}$. (C) M-mode ultrasound at mid ventricle level. At $2 \mathrm{~d}$ after $\mathrm{Ml} / \mathrm{R}$, there was akinesis of anterolateral wall (red arrow) and significant decrease in fractional shortening, compared with that of sham-operated animals. the anterolateral wall of the left ventricle was observed with ${ }^{18}$ F-FDG PET (Fig. 1B). At $2 \mathrm{~d}$ after MI/R, akinesis of the anterolateral wall with a significant decrease in cardiac function was identified by $M$ mode high-resolution ultrasound (Fig. 1C). Fractional shortening was decreased from $51 \% \pm 4.5 \%$ to $32 \% \pm 2.8 \%$ in rats after ischemia-reperfusion. As was expected, neither uptake defect nor compromised cardiac function was observed from ${ }^{18} \mathrm{~F}-\mathrm{FDG}$ PET and M-mode high-resolution ultrasound in sham-operated animals.

\section{Image Colocalization}

Intensive ${ }^{18} \mathrm{~F}$-FDG uptake in the myocardium is due to the high metabolic rate (27). Thus, ${ }^{18} \mathrm{~F}-\mathrm{FDG}$ PET provides an anatomic reference to the site of infarction and reflects the reduced metabolism of the infarcted area. To facilitate image coregistration, the position of the animal was precisely maintained in the scanning gantry during both tracer injections and imaging process. Representative myocardial transaxial slices from the same animal after in vivo PET of ${ }^{18} \mathrm{~F}$-FBEM-Cys ${ }^{40}$-exendin-4 and ${ }^{18} \mathrm{~F}$-FDG are presented in Figure 2A. High and homogeneous ${ }^{18} \mathrm{~F}-\mathrm{FDG}$ accumulation was visualized in the heart of the sham group whereas almost no ${ }^{18}$ F-FBEM-Cys ${ }^{40}$-exendin-4 uptake was observed. Compared with sham-operated rats, the heart in $\mathrm{MI} / \mathrm{R}$ rats showed decreased ${ }^{18} \mathrm{~F}$-FDG uptake in the anterolateral wall of the left ventricle at $1 \mathrm{~d}$ after surgery. ${ }^{18} \mathrm{~F}$ FBEM-Cys ${ }^{40}$-exendin-4 localization was observed within the myocardium in the rats after MI/R. Moreover, the localization matched perfectly with the areas of infarcted/ ischemic myocardium, as evidenced by decreased ${ }^{18} \mathrm{~F}$ FDG uptake.

To further confirm the anatomic localization of ${ }^{18} \mathrm{~F}$ FBEM-Cys ${ }^{40}$-exendin-4 PET, we obtained a CT scan for the same animal with a docked PET/CT system. Representative transaxial slices of PET and CT scans are shown in Figure 2B. The fused images clearly showed localization of ${ }^{18} \mathrm{~F}$-FBEM-Cys ${ }^{40}$-exendin-4 within the myocardium at $1 \mathrm{~d}$ after MI/R. ${ }^{18}$ F-FBEM-cys ${ }^{40}$-exendin-4 signal detected with PET corresponded to anterolateral myocardium and was clearly separated from the intercostal muscle layer.

\section{Time Frame of GLP-1R Expression by PET}

To evaluate GLP-1R expression after MI/R, longitudinal PET was performed at $8 \mathrm{~h}(n=5), 1 \mathrm{~d}(n=5), 3 \mathrm{~d}(n=5)$, $1 \mathrm{wk}(n=5)$, and $2 \mathrm{wk}(n=3)$ after surgery using ${ }^{18} \mathrm{~F}-$ FBEM-Cys ${ }^{40}$-exendin-4 as the imaging probe. Figure $3 \mathrm{~A}$ shows representative transaxial PET images acquired at different time points after MI/R. In all rats, lung uptake of ${ }^{18} \mathrm{~F}$-FBEM-Cys ${ }^{40}$-exendin-4 was observed because of the high level of endogenous GLP-1R expression (9). Com-

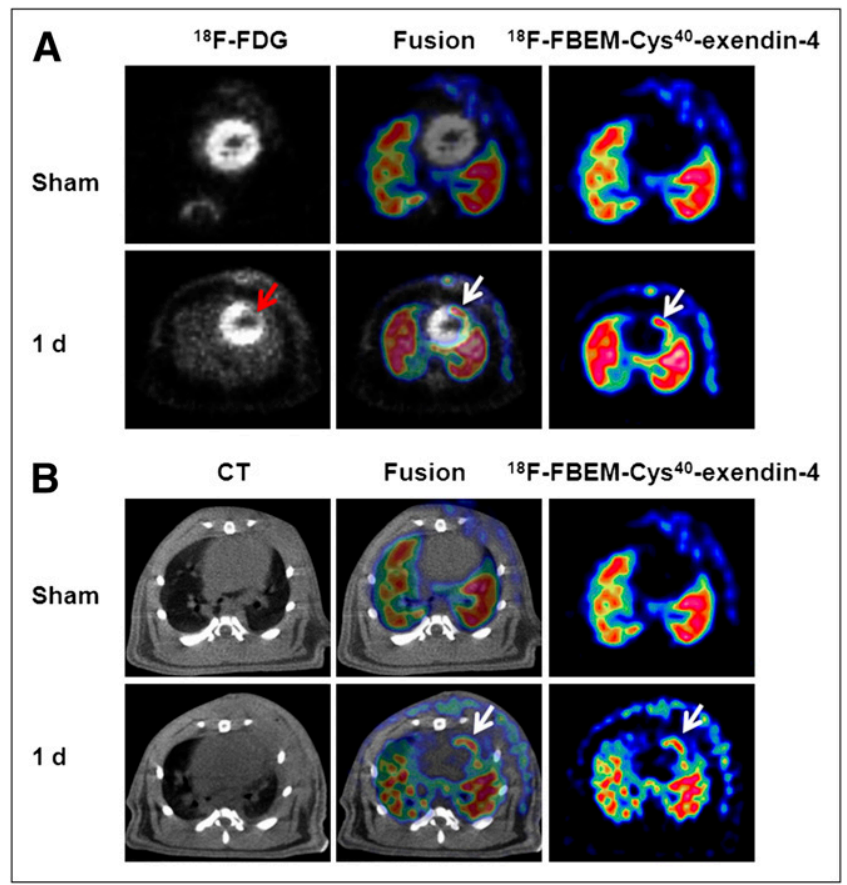

FIGURE 2. Coregistration of ${ }^{18} \mathrm{~F}-\mathrm{FBEM}$-cys ${ }^{40}$-exendin-4 PET with ${ }^{18}$ F-FDG PET (A) and CT scan (B). Transaxial sections were adapted for image fusion. (A) Coronary artery ligation resulted in decrease of ${ }^{18} \mathrm{~F}-\mathrm{FDG}$ uptake (red arrow) and increased uptake of ${ }^{18} \mathrm{~F}-\mathrm{FBEM}-$ cys $^{40}$-exendin-4 (white arrow). Fusion of both scans results in perfect colocalization of decreased ${ }^{18} \mathrm{~F}-\mathrm{FDG}$ and increased ${ }^{18} \mathrm{~F}$-FBEM-cys ${ }^{40}$ exendin-4 uptake. (B) PET/CT fused images demonstrated myocardial origin of ${ }^{18} \mathrm{~F}-\mathrm{FBEM}$-cys ${ }^{40}$-exendin-4 PET signal after MI/R. ${ }^{18} \mathrm{~F}-\mathrm{FBEM}$-cys ${ }^{40}$-exendin-4 signal detected with PET corresponds to anterolateral myocardium and is clearly separated from intercostal muscle layer. 


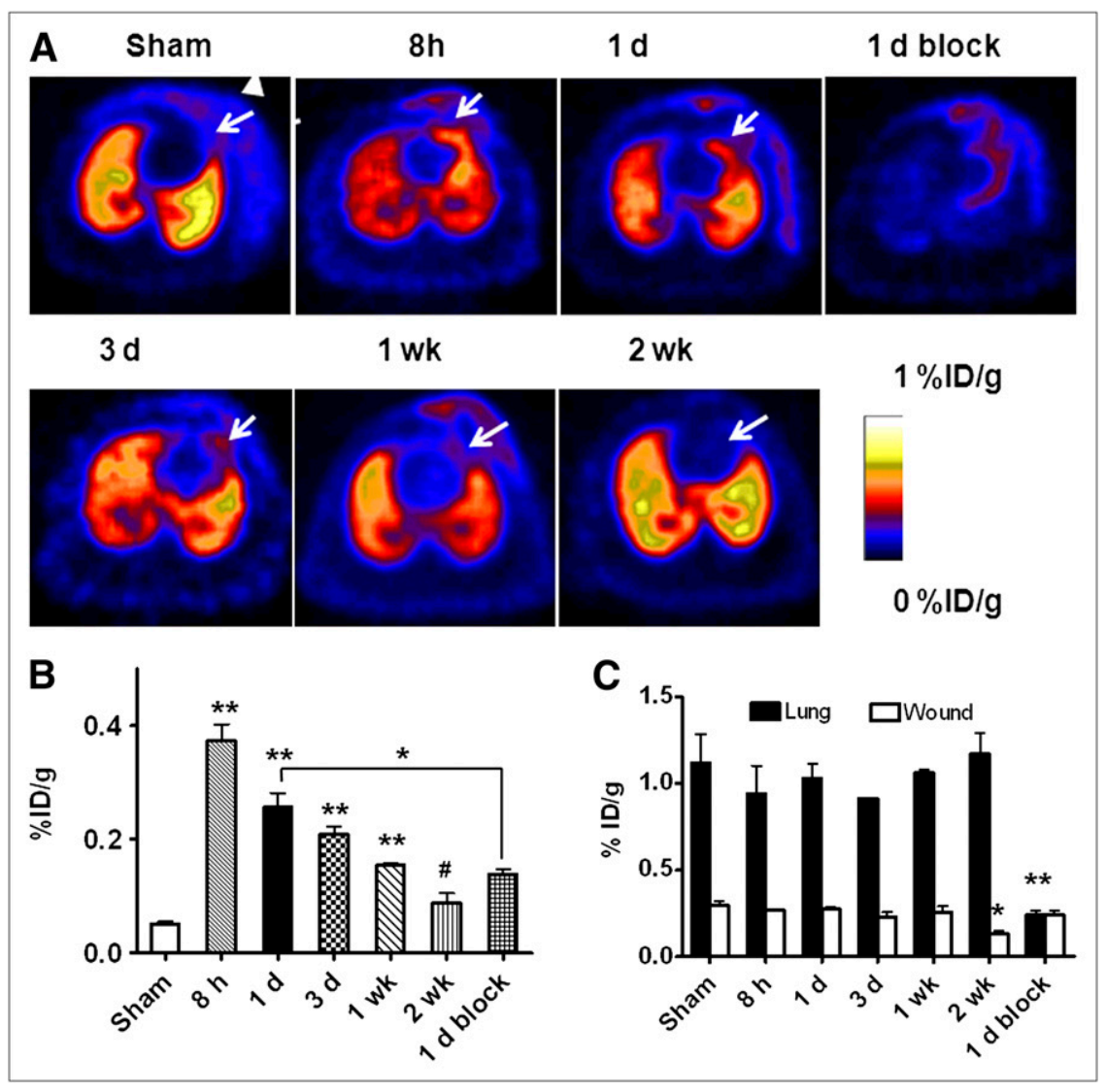

FIGURE 3. PET of GLP1-R expression using ${ }^{18} \mathrm{~F}-\mathrm{FBEM}$-cys ${ }^{40}$-exendin-4. (A) Representative transaxial $P E T$ images using ${ }^{18} \mathrm{~F}$-FBEM-cys ${ }^{40}$-exendin-4 at different times after $\mathrm{Ml} / \mathrm{R}$. High ${ }^{18} \mathrm{~F}-\mathrm{FBEM}$-cys ${ }^{40}$ exendin-4 uptake region from infarcted/ ischemic myocardium is indicated by white arrows, and triangle indicates ${ }^{18} \mathrm{~F}-\mathrm{FBEM}-$ cys $^{40}$-exendin-4 signal from surgical wound, which is present in both sham-operated and $\mathrm{MI} / \mathrm{R}$ animals. (B) Quantification of ${ }^{18} \mathrm{~F}$ FBEM-cys ${ }^{40}$-exendin-4 uptake in infarcted/ ischemic myocardium after $\mathrm{Ml} / \mathrm{R}$ over time, expressed as \%ID/g of tissue. ${ }^{18} \mathrm{~F}-\mathrm{FBEM}$ cys ${ }^{40}$-exendin-4 uptake was highest at $8 \mathrm{~h}$ after operation, compared with sham group. (C) Quantification of ${ }^{18} \mathrm{~F}$-FBEM-cys ${ }^{40}$-exendin-4 uptake in lung and surgical wound region after $\mathrm{MI} / \mathrm{R}$ over time, expressed as $\% \mathrm{ID} / \mathrm{g}$ of tissue. ${ }^{\star} P<0.05 .{ }^{\star} P<0.01$. ${ }^{\#} P>0.05$.

pared with the control group, localized tracer uptake was observed as early as $8 \mathrm{~h}$ after MI/R. The positive signal persisted at a relatively high level at 1 and $3 \mathrm{~d}$ and then decreased from $1 \mathrm{wk}$ after MI/R. At 2 wk after MI/R, almost no tracer accumulation was observed in the infarcted/ischemic region. Minimal tracer uptake was also identified in the area of the surgical wound.

The quantitative results based on PET are presented in Figure 3B. The uptake of ${ }^{18} \mathrm{~F}-\mathrm{FBEM}-\mathrm{Cys}^{40}{ }^{4}$-exendin- 4 in healthy myocardium in the sham-operated rats at $1 \mathrm{~d}$ after surgery was as low as $0.05 \pm 0.007 \% \mathrm{ID} / \mathrm{g}$. MI/R induction was associated with a significant increase in ${ }^{18} \mathrm{~F}$-FBEM$\mathrm{Cys}^{40}$-exendin- 4 uptake in the anterolateral wall of the myocardium. At $8 \mathrm{~h}$ after MI/R, tracer uptake in the infarcted/ischemic region was $0.37 \pm 0.05 \% \mathrm{ID} / \mathrm{g}$, significantly higher than that in the control group $(P<0.01)$. The localized tracer uptake decreased but remained elevated, compared with controls, at 1 and $3 \mathrm{~d}(0.29 \pm$ 0.015 and $0.21 \pm 0.024 \% \mathrm{ID} / \mathrm{g}$, respectively; $P<0.05$ and $P<0.01$, respectively). The uptake of ${ }^{18}$ F-FBEM$\mathrm{Cys}^{40}$-exendin-4 kept dropping with time to $0.15 \pm 0.005$ $\% \mathrm{ID} / \mathrm{g}$ at $7 \mathrm{~d}$ after MI/R $(P<0.01)$. At $14 \mathrm{~d}$ after MI/R, the tracer uptake in the affected area showed no significant difference from that in the healthy myocardium $(0.087 \pm$ $0.018 \% \mathrm{ID} / \mathrm{g}, P>0.05)$.

To further confirm the GLP-1R binding specificity of ${ }^{18} \mathrm{~F}-$ FBEM-Cys ${ }^{40}$-exendin- 4 , we used nonradiolabeled exendin-4 as a blocking agent. It is clear that tracer uptake in the in- farcted myocardium could be blocked by an excess amount of unlabeled exendin- 4 peptide. The tracer uptake was significantly lower than that in the unblocked rats at $1 \mathrm{~d}$ after MI/R $(0.14 \pm 0.01$ vs. $0.26 \pm 0.04 \% \mathrm{ID} / \mathrm{g}$, respectively; $P<$ $0.05)$.

The lung uptake in sham-operated rats is $1.12 \pm 0.29 \%$ ID/g. MI/R did not affect lung uptake of ${ }^{18}$ F-FBEM-Cys ${ }^{40}{ }_{-}$ exendin-4 significantly (Fig. 3C). An excess amount of unlabeled exendin-4 blocked lung uptake $(P<0.01)$. ${ }^{18} \mathrm{~F}$-FBEM-Cys ${ }^{40}$-exendin-4 uptake within the surgical wound was $0.30 \pm 0.04 \% \mathrm{ID} / \mathrm{g}$ and remained essentially unchanged until 2 wk after surgery, at which time the uptake dropped to $0.13 \pm 0.02 \% \mathrm{ID} / \mathrm{g}$. In addition, an excess amount of unlabeled exendin- 4 did not affect tracer uptake in the surgical wound $(0.24 \pm 0.05 \% \mathrm{ID} / \mathrm{g}, P>0.05)$.

\section{Autoradiography}

In parallel to in vivo PET, we performed ex vivo autoradiography to validate the quantitative results based on PET images. Typical autoradiographs and averaged uptake ratios in different time points are shown in Figure 4. At early time points until $3 \mathrm{~d}$ after MI/R, increased signal intensity was clearly seen in the infarcted/ischemic area. Moreover, the signal was localized within the infarcted/ ischemic area, as evidenced by TTC and HE staining. Quantitative data demonstrated a trend similar to the results from PET. The uptake ratio of ${ }^{18} \mathrm{~F}$-FBEM-Cys ${ }^{40}$-exendin- 4 in the infarcted/ischemic area, compared with unaffected 


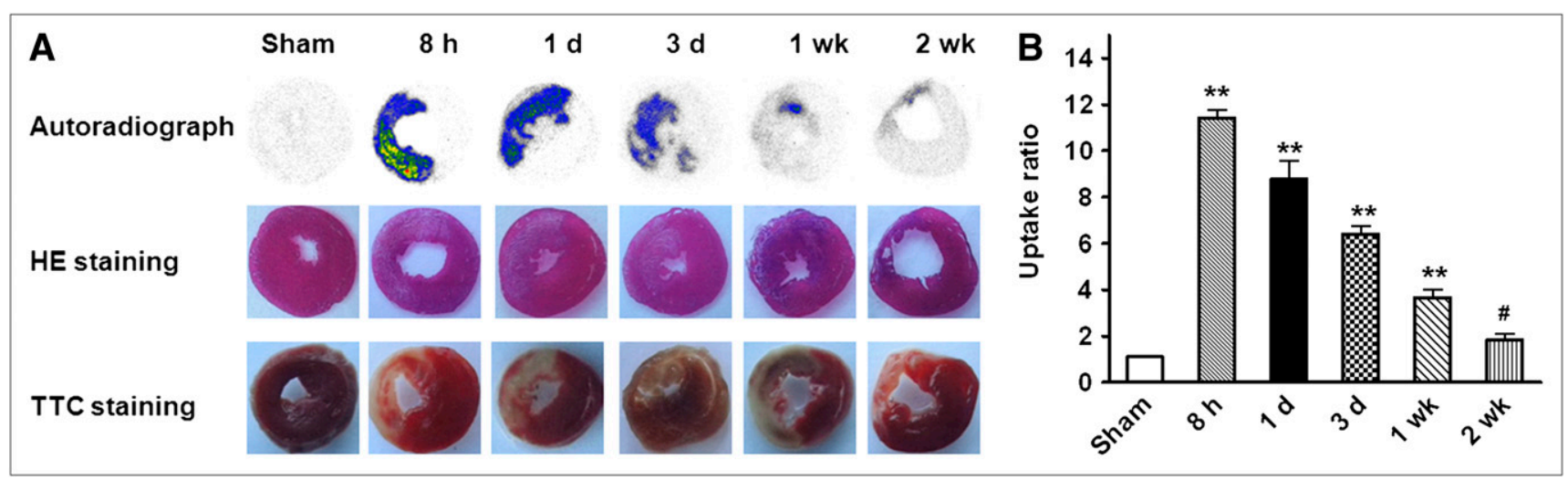

FIGURE 4. (A) Representative autoradiographs of ${ }^{18} \mathrm{~F}-\mathrm{FBEM}-\mathrm{cys}^{40}$-exendin-4 uptake in myocardium and corresponding $\mathrm{HE}$ and $\mathrm{TTC}$ staining on adjacent slices from same animal at different time points after MI/R. (B) Time course of myocardial ${ }^{18} \mathrm{~F}-\mathrm{FBEM}-\mathrm{cys}{ }^{40}$-exendin-4 uptake ratios (vs. remote myocardium) after MI/R determined by autoradiography. ${ }^{*} P<0.05 .{ }^{*} P<0.01$. ${ }^{\#} P>0.05$.

myocardium, was the highest at $8 \mathrm{~h}$ after MI/R and decreased with time. At $2 \mathrm{wk}$ after $\mathrm{MI} / \mathrm{R}$, almost no signal was detected in the infarcted/ischemic myocardium.

\section{Western Blot and Histologic Staining}

It is expected that increased uptake of ${ }^{18} \mathrm{~F}-\mathrm{FBEM}-\mathrm{Cys}^{40}{ }_{-}$ exendin-4 in the infarcted/ischemic area within myocardium is mainly due to upregulation of the targeting protein receptor GLP1-R. Therefore, we performed Western blotting using GLP-1R-specific antibody on myocardial samples from both sham-operated and MI/R rats. As shown in Figure 5, the GLP-1R protein level was markedly increased in ischemic myocardium at $1 \mathrm{~d}$ after MI/R, compared with the sham group $(P<0.05)$. To further characterize the expression and distribution of GLP-1R microscopically, we performed immunohistochemical staining of myocardial tissue sections against GLP-1R. The staining results are presented in Figure 6. Few GLP-1R-positive signals were present on healthy myocardium from the sham-operated group. As we expected, in cardiac sections adjacent to the site of the infarcted/ischemic myocardium, enhanced and predominant sarcolemmal staining of GLP-1R was observed on infarcted/ischemic myocardium at $8 \mathrm{~h}$ and $1 \mathrm{~d}$ after MI/R. The signal positivity decreased along with time and returned to a normal level at $2 \mathrm{wk}$ after MI/R (Fig. 6A). Both immunohistochemical and HE staining also showed coagulative necrosis and the loss of nuclei. Apparent infiltration of neutrophils into the interstitium was observed, especially at day 3 after MI/R.

To further identify the target cells of GLP-1R overexpression, we costained GLP-1R and CD11b, a leukocyte marker (28). Compared with normal myocardium, the infarcted/ischemic myocardium showed apparent leukocyte infiltration as evidenced by strong green fluorescence signal (Fig. 6B). The infarcted/ischemic myocardium also showed a much stronger red fluorescence signal, indicating an overexpression of GLP-1R after MI/R. Moreover, no colocalization of GLP-1R and CD11b was identified.

\section{DISCUSSION}

GLP-1 and its analogs have been shown to exert cardiovascular effects in several experimental models and preliminary clinical trials (29-31). After acute myocardial infarction, an increased inotropic effect was noted in patients receiving GLP-1(7-36) amide infusion for up to $3 \mathrm{~d}$ after successful reperfusion (32). A pilot study of GLP-1 administration for $72 \mathrm{~h}$ in human subjects with LV

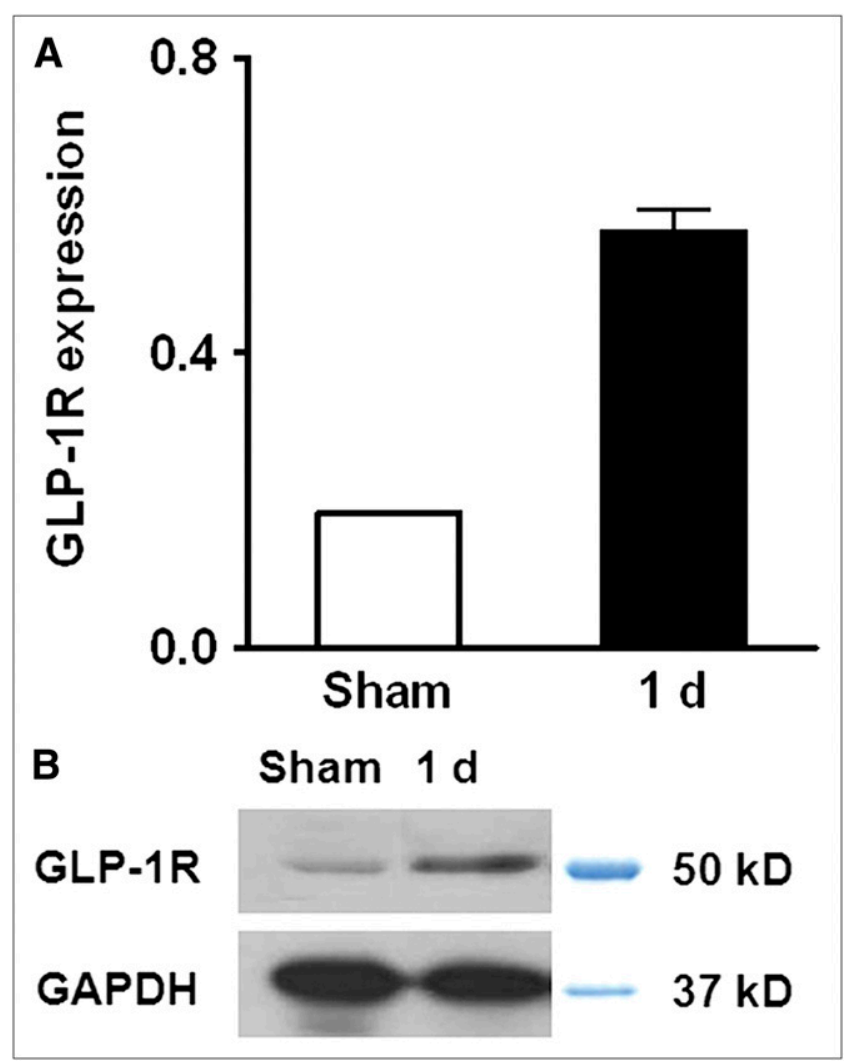

FIGURE 5. Semiquantitative analysis (A) and Western blot (B) of GLP-1R in anterolateral wall of heart from sham-operated and 1-d reperfusion groups. 


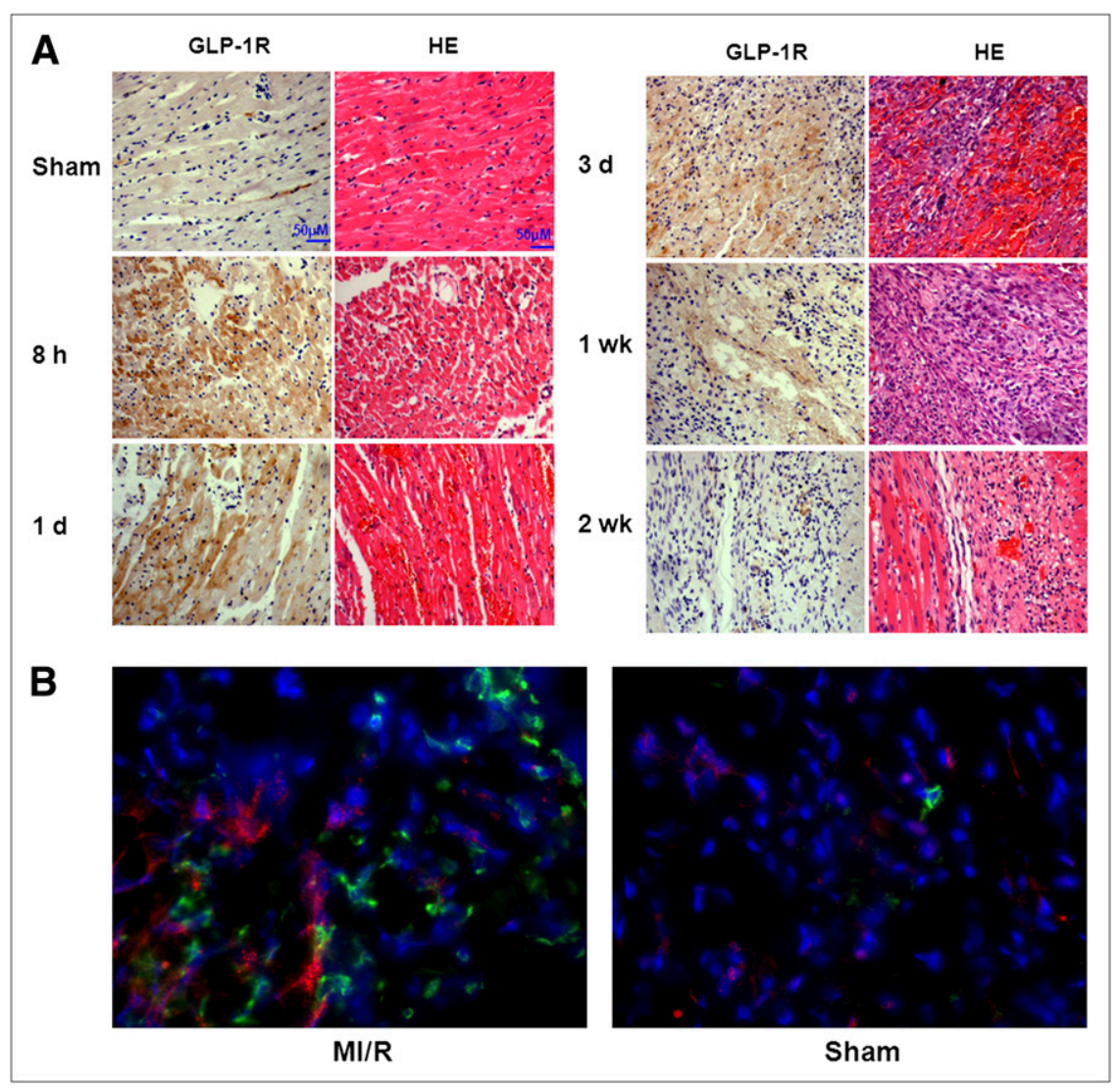

FIGURE 6. (A) Histology with HE and GLP$1 \mathrm{R}$ immunohistochemical analysis in normal myocardium and infarcted/ischemic myocardium at different time points after coronary occlusion and reperfusion. (B) Fluorescent immunostaining of myocardium sections with anti-GLP-1R (red) and anti-CD11b (green) antibodies. Nuclei are counterstained with 4',6-diamidino-2-phenylindole (blue).

dysfunction after myocardial injury and angioplasty demonstrated a reduced hospital stay and improved global and regional LV wall motion scores (32). The mechanisms through which GLP-1 can modulate cardiac function are complex and incompletely understood (10). However, it has been widely accepted that GLP-1 exerts a direct cytoprotective effect via inhibition of apoptosis directly in target cells expressing GLP-1R through both cyclic adenosine monophosphate and phosphoinositide 3-kinase pathways $(10,11)$.

The expression of GLP-1R in the heart has been confirmed previously $(9,33)$. However, the dynamic pattern of GLP-1R after $\mathrm{MI} / \mathrm{R}$ and the following remodeling process has never, to our knowledge, been investigated. In this study, for the first time, we applied the GLP-1R-specific imaging tracer ${ }^{18} \mathrm{~F}-\mathrm{FBEM}-\mathrm{Cys}{ }^{40}{ }^{-}$-exendin-4 to visualize and quantify the temporal changes of GLP1-R expression in a rat myocardial ischemia/reperfusion model. Increased focal tracer retention was observed as early as $8 \mathrm{~h}$ after the onset of ischemia, and the tracer accumulation decreased along with time in the infarcted and periinfarct zones. At $2 \mathrm{wk}$ after MI/R, ${ }^{18} \mathrm{~F}$-FBEM$\mathrm{Cys}^{40}$-exendin-4 uptake within the myocardium was restored to a normal level. Thus, with noninvasive molecular imaging, we revealed the kinetics of GLP-1R expression in the affected myocardium. However, the mechanism of MI/R-induced GLP-1R upregulation is still unclear and will need further investigation. Western blot confirmed that protein level increased after MI/R. The membrane presentation of the receptor may also be affected at the same time (34).
Besides early-stage infarcted/ischemic myocardium, the lung region also showed a high level of ${ }^{18} \mathrm{~F}-\mathrm{FBEM}-\mathrm{Cys}^{40}{ }_{-}$ exendin- 4 accumulation, mainly because of a high level of GLP-1R expression (9). With the coinjection of an excess amount of unlabeled exendin-4 peptide, tracer uptake in the lung was blocked significantly (Fig. 3C), indicating that the lung accumulation of ${ }^{18} \mathrm{~F}$-FBEM-Cys ${ }^{40}$-exendin-4 was GLP$1 \mathrm{R}-$-specific. No apparent change of uptake value in the myocardium was observed at any of the time points examined in either the sham-operated group or the MI/R rats. Lungs and kidneys of humans express significantly lower levels of GLP-1 receptor than those of rats and mice (35). However, the observed high level of uptake in the lung region may compromise any potential translation of the GLP-1R-specific tracer to the clinic. This problem can be addressed by adjunctive scans of either anatomy or myocardial perfusion to identify the location of the heart. We also noticed that the surgical wound showed increased tracer uptake that cannot be blocked with unlabeled exendin-4. Thus, the elevated uptake in the surgical wound may result from increased blood flow and vascular permeability during tissue remodeling and an inflammatory reaction.

Transient ischemia for up to 20 min resulted in increased ${ }^{18} \mathrm{~F}-\mathrm{FDG}$ uptake in the ischemic segment due to a metabolism switch (36). In this study, we occluded a coronary artery for $45 \mathrm{~min}$ and found that the infarcted/ischemic segment showed decreased ${ }^{18} \mathrm{~F}$-FDG uptake as illustrated in Figure 2A. At $3 \mathrm{~d}$ after $\mathrm{MI} / \mathrm{R}$, we observed increased ${ }^{18} \mathrm{~F}-\mathrm{FDG}$ 
uptake in the infarcted/ischemic area (data not shown). Apparent infiltration of neutrophils was observed at the 3-d and 1 -wk time points, possibly accounting partially for the increased ${ }^{18}$ F-FDG uptake because inflammatory cells such as activated granulocytes, lymphocytes, and macrophages have enhanced glycolysis (37). In a recent study, Lee et al. (38) observed significantly increased ${ }^{18} \mathrm{~F}-\mathrm{FDG}$ uptake in the myocardium of infarcted mice at day 5 after coronary ligation, compared with the control mice. They also confirmed that within subacutely infarcted myocardium, ${ }^{18} \mathrm{~F}$-FDG accumulated mostly in monocytes or macrophages. Unlike ${ }^{18} \mathrm{~F}-\mathrm{FDG}$, infarcted/ischemic myocardium showed significantly lower ${ }^{18}$ F-FBEM-Cys ${ }^{40}$-exendin-4 uptake at day 3, compared with $8 \mathrm{~h}$ and day 1 after MI/R, indicating that GLP-1R upregulation is likely independent of an inflammatory reaction during tissue remodeling. No colocalization of GLP-1R and CD11b further excluded the involvement of infiltrated neutrophils in increased uptake of ${ }^{18} \mathrm{~F}-\mathrm{FBEM}-\mathrm{Cys}{ }^{40}$-exendin-4 in infarcted/ ischemic myocardium (Fig. 6B).

In a previous study, we performed longitudinal PET using ${ }^{18}$ F-AIF-NOTA-PRGD2 to monitor quantitatively integrin $\alpha_{\mathrm{v}} \beta_{3}$ changes after MI/R (39). Focal accumulation of ${ }^{18} \mathrm{~F}-\mathrm{AlF}-$ NOTA-RGD2 in the infarct area started at day 3 and reached a plateau between 1 and $3 \mathrm{wk}$. Even after $4 \mathrm{mo}$, the focal accumulation remained at a higher level than in the sham group. The similar distribution pattern of arginine-glycineaspartic acid-based tracer in models of myocardial ischemia has been observed by other groups $(40,41)$. In contrast, ${ }^{18} \mathrm{~F}$-FBEM-Cys ${ }^{40}$-exendin- 4 showed a dramatically different uptake pattern. At $1 \mathrm{wk}$ after MI/R, the localized signal was already low and was reduced to a normal level at 2 wk after $\mathrm{MI} / \mathrm{R}$.

These results imply that therapy with GLP-1 and its analogs will be more effective at early time points after MI/R, when the receptor expression is at a relatively high level. After $2 \mathrm{wk}$, the therapeutic effect may be compromised because of low receptor expression. Indeed, several reported therapy protocols all involved the administration of GLP-1R agonists at the early stage of acute cardiac infarction $(29,32)$. The cardioprotective effect of GLP-1 has been observed in transgenic mice without GLP1-R expression, indicating that a GLP-1R-independent pathway exists (9). An improved LV function was observed in patients with chronic heart failure after a 5-wk continuous subcutaneous infusion of GLP-1(7-36) (31). However, the GLP-1R expression in myocardium with chronic heart failure needs further investigation to better clarify the cardioprotective pathways involved.

\section{CONCLUSION}

PET using ${ }^{18}$ F-FBEM-Cys ${ }^{40}$-exendin-4 allows the longitudinal noninvasive visualization of GLP-1R upregulation induced by ischemia-reperfusion. After MI/R, the GLP-1R rapidly increases over the first $8 \mathrm{~h}$ and then slowly returns to baseline over the subsequent $7 \mathrm{~d}$. The imaging results will be helpful to better understand the mechanism of the cardioprotective effect of GLP-1 and its analogs. In addition, it also can provide guidance to optimize the time frame of therapeutic intervention.

\section{DISCLOSURE STATEMENT}

The costs of publication of this article were defrayed in part by the payment of page charges. Therefore, and solely to indicate this fact, this article is hereby marked "advertisement" in accordance with 18 USC section 1734.

\section{ACKNOWLEDGMENTS}

This project was supported, in part, by the National Basic Research Program of China (973 program, 2013CB733802), the National Science Foundation of China (NSFC) (81028009, 81100234), the Chinese Academy of Sciences professorship for Senior International Scientists (2011T2J06), and the Intramural Research Program of the National Institute of Biomedical Imaging and Bioengineering (NIBIB), the National Institutes of Health (NIH). No other potential conflict of interest relevant to this article was reported.

\section{REFERENCES}

1. Yellon DM, Hausenloy DJ. Myocardial reperfusion injury. $N$ Engl $J$ Med. 2007;357:1121-1135.

2. Jennings RB, Sommers HM, Smyth GA, Flack HA, Linn H. Myocardial necrosis induced by temporary occlusion of a coronary artery in the dog. Arch Pathol. 1960;70:68-78.

3. Jordan JE, Zhao ZQ, Vinten-Johansen J. The role of neutrophils in myocardial ischemia-reperfusion injury. Cardiovasc Res. 1999;43:860-878.

4. Lavi S, Lavi R. Conditioning of the heart: from pharmacological interventions to local and remote protection: possible implications for clinical practice. Int $J$ Cardiol. 2011;146:311-318.

5. Yang X, Cohen MV, Downey JM. Mechanism of cardioprotection by early ischemic preconditioning. Cardiovasc Drugs Ther. 2010;24:225-234.

6. Holst JJ, Deacon CF, Vilsboll T, Krarup T, Madsbad S. Glucagon-like peptide-1, glucose homeostasis and diabetes. Trends Mol Med. 2008;14:161-168.

7. Reubi JC, Waser B. Concomitant expression of several peptide receptors in neuroendocrine tumours: molecular basis for in vivo multireceptor tumour targeting. Eur J Nucl Med Mol Imaging. 2003;30:781-793.

8. Bose AK, Mocanu MM, Carr RD, Brand CL, Yellon DM. Glucagon-like peptide 1 can directly protect the heart against ischemia/reperfusion injury. Diabetes. 2005;54:146-151.

9. Ban K, Noyan-Ashraf MH, Hoefer J, Bolz SS, Drucker DJ, Husain M. Cardioprotective and vasodilatory actions of glucagon-like peptide 1 receptor are mediated through both glucagon-like peptide 1 receptor-dependent and -independent pathways. Circulation. 2008; 117:2340-2350.

10. Noyan-Ashraf MH, Momen MA, Ban K, et al. GLP-1R agonist liraglutide activates cytoprotective pathways and improves outcomes after experimental myocardial infarction in mice. Diabetes. 2009;58:975-983.

11. Hausenloy DJ, Yellon DM. New directions for protecting the heart against ischaemia-reperfusion injury: targeting the reperfusion injury salvage kinase (RISK)-pathway. Cardiovasc Res. 2004;61:448-460.

12. Tong H, Chen W, Steenbergen C, Murphy E. Ischemic preconditioning activates phosphatidylinositol-3-kinase upstream of protein kinase C. Circ Res. 2000;87: 309-315.

13. Yin F, Liu JH, Zheng XX, Guo LX. GLP-1 receptor plays a critical role in geniposide-induced expression of heme oxygenase-1 in PC12 cells. Acta Pharmacol Sin. 2010;31:540-545.

14. Liu X, Pachori AS, Ward CA, et al. Heme oxygenase-1 (HO-1) inhibits postmyocardial infarct remodeling and restores ventricular function. FASEB J. 2006;20:207-216. 
15. Deacon CF, Johnsen AH, Holst JJ. Degradation of glucagon-like peptide-1 by human plasma in-vitro yields an N-terminally truncated peptide that is a major endogenous metabolite in-vivo. J Clin Endocrinol Metab. 1995;80:952-957.

16. Wild D, Behe M, Wicki A, et al. [Lys ${ }^{40}\left(\right.$ Ahx-DTPA- $\left.\left.{ }^{111} \mathrm{In}\right) \mathrm{NH}_{2}\right]$ exendin-4, a very promising ligand for glucagon-like peptide-1 (GLP-1) receptor targeting. J Nucl Med. 2006;47:2025-2033.

17. Wild D, Wicki A, Mansi R, et al. Exendin-4-based radiopharmaceuticals for glucagonlike peptide-1 receptor PET/CT and SPECT/CT. J Nucl Med. 2010;51: 1059-1067.

18. Brom M, Oyen WJ, Joosten L, Gotthardt M, Boerman OC. ${ }^{68}$ Ga-labelled exendin-3, a new agent for the detection of insulinomas with PET. Eur J Nucl Med Mol Imaging. 2010;37:1345-1355.

19. Eng J, Kleinman WA, Singh L, Singh G, Raufman JP. Isolation and characterization of exendin-4, an exendin-3 analogue, from Heloderma suspectum venom. Further evidence for an exendin receptor on dispersed acini from guinea pig pancreas. J Biol Chem. 1992;267:7402-7405.

20. Gao H, Niu G, Yang M, et al. PET of insulinoma using ${ }^{18}$ F-FBEM-EM3106B, a new GLP-1 analogue. Mol Pharm. 2011;8:1775-1782.

21. Kiesewetter DO, Gao H, Ma Y, et al. ${ }^{18} \mathrm{~F}$-radiolabeled analogs of exendin-4 for PET imaging of GLP-1 in insulinoma. Eur J Nucl Med Mol Imaging. 2012; 39:463-473.

22. Kiesewetter DO, Jacobson O, Lang L, Chen X. Automated radiochemical synthesis of $\left[{ }^{18} \mathrm{~F}\right] \mathrm{FBEM}$ : a thiol reactive synthon for radiofluorination of peptides and proteins. Appl Radiat Isot. 2011;69:410-414.

23. Guide for the Care and Use of Laboratory Animals. Washington, DC: National Academy Press; 2010.

24. Wu JC, Chen IY, Wang Y, et al. Molecular imaging of the kinetics of vascular endothelial growth factor gene expression in ischemic myocardium. Circulation. 2004;110:685-691.

25. Rodriguez-Porcel M, Gheysens O, Chen IY, Wu JC, Gambhir SS. Image-guided cardiac cell delivery using high-resolution small-animal ultrasound. Mol Ther. 2005;12:1142-1147.

26. Yang M, Gao H, Yan Y, et al. PET imaging of early response to the tyrosine kinase inhibitor ZD4190. Eur J Nucl Med Mol Imaging. 2011;38:1237-1247.

27. Sun $\mathrm{X}$, Yan $\mathrm{Y}$, Liu S, et al. ${ }^{18} \mathrm{~F}-\mathrm{FPPRGD}{ }_{2}$ and ${ }^{18} \mathrm{~F}-\mathrm{FDG}$ PET of response to Abraxane therapy. J Nucl Med. 2011;52:140-146.

28. Mazzone A, Ricevuti G. Leukocyte CD11/CD18 integrins: biological and clinical relevance. Haematologica. 1995;80:161-175.
29. Sonne DP, Engstrom T, Treiman M. Protective effects of GLP-1 analogues exendin-4 and GLP-1(9-36) amide against ischemia-reperfusion injury in rat heart. Regul Pept. 2008;146:243-249.

30. Nikolaidis LA, Elahi D, Hentosz T, et al. Recombinant glucagon-like peptide-1 increases myocardial glucose uptake and improves left ventricular performance in conscious dogs with pacing-induced dilated cardiomyopathy. Circulation. 2004;110:955-961.

31. Sokos GG, Nikolaidis LA, Mankad S, Elahi D, Shannon RP. Glucagon-like peptide-1 infusion improves left ventricular ejection fraction and functional status in patients with chronic heart failure. J Card Fail. 2006;12:694-699.

32. Nikolaidis LA, Mankad S, Sokos GG, et al. Effects of glucagon-like peptide-1 in patients with acute myocardial infarction and left ventricular dysfunction after successful reperfusion. Circulation. 2004;109:962-965.

33. Bullock BP, Heller RS, Habener JF. Tissue distribution of messenger ribonucleic acid encoding the rat glucagon-like peptide-1 receptor. Endocrinology. 1996; 137:2968-2978.

34. Citri A, Alroy I, Lavi S, et al. Drug-induced ubiquitylation and degradation of ErbB receptor tyrosine kinases: implications for cancer therapy. EMBO J. 2002; 21:2407-2417.

35. Körner M, Stockli M, Waser B, Reubi JC. GLP-1 receptor expression in human tumors and human normal tissues: potential for in vivo targeting. J Nucl Med. 2007; 48:736-743.

36. Schelbert HR, Henze E, Phelps ME, Kuhl DE. Assessment of regional myocardial ischemia by positron-emission computed tomography. Am Heart J. 1982;103:588-597.

37. Rosenbaum SJ, Lind T, Antoch G, Bockisch A. False-positive FDG PET uptakethe role of PET/CT. Eur Radiol. 2006;16:1054-1065.

38. Lee WW, Marinelli B, van der Laan AM, et al. PET/MRI of inflammation in myocardial infarction. J Am Coll Cardiol. 2012;59:153-163.

39. Gao H, Lang L, Guo N, et al. PET imaging of angiogenesis after myocardial infarction/reperfusion using a one-step labeled integrin-targeted tracer ${ }^{18} \mathrm{~F}-\mathrm{AlF}$ NOTA-PRGD 2 . Eur J Nucl Med Mol Imaging. 2012;39:683-692.

40. van den Borne SW, Isobe S, Verjans JW, et al. Molecular imaging of interstitial alterations in remodeling myocardium after myocardial infarction. $J$ Am Coll Cardiol. 2008;52:2017-2028.

41. Higuchi T, Bengel FM, Seidl S, et al. Assessment of $\alpha v \beta 3$ integrin expression after myocardial infarction by positron emission tomography. Cardiovasc Res. 2008;78:395-403. 